\title{
Chemical Constituents of Essential Oils from Resin and Bark of Agathis borneensis
}

\author{
FOUZIAH BINTI ALET, ZAINI BIN ASSIM*, ISMAIL BIN JUSOH \& \\ FASIHUDDIN BADRUDDIN AHMAD \\ Department of Chemistry, Faculty of Resource Science and Technology \\ Universiti Malaysia Sarawak, 94300 Kota Samarahan, Sarawak, Malaysia.
}

\begin{abstract}
The chemical constituents of essential oils obtained from resin and bark of Agathis borneensis were analysed using capillary gas chromatography-flame ionization detector (GC-FID) and gas chromatography-mass spectrometer (GC/MS). The resin essential oil dominated by $\alpha$-pinene $(30.93 \%), \delta$-limonene $(17.79 \%), \beta$-pinene $(11.28 \%)$ and terpinen-4-ol $(8.35 \%)$. The main components in the bark essential oil were $\beta$-pinene $(8.68 \%)$, terpinen-4-ol (8.54\%), $\alpha$-pinene (8.50\%) and $\alpha$-terpineol (8.48\%).
\end{abstract}

Keywords: Essential oil, gas chromatography, Agathis borneensis, resin, bark

\section{INTRODUCTION}

Agathis sbp. belong to the family Araucariaceae. Araucariaceae comprises of three genera which are Agathis, Araucaria and Wollemia with over 40 species. Araucariaceae are evergreen conifers that can be found in warm temperate regions of the southern hemisphere, with the exception of Southern Africa (Brophy et al. 2000). Agathis species can be found in Philippines, Moluccas, Celebes, Borneo and Peninsular Malaysia. This genus is very important as high value timber and has a valuable resin which is used as varnishes and lacquers (Appanah and Weinland 1993).

Savluchinske-Feio et al. (2006) showed that the resin acid derivatives from this genus have shown several bioactivities such as antifungal and antibacterial. Agathis borneensis also known by several vernacular names such as "Bindang" in Sarawak, "Damar Minyak" in Peninsular Malaysia, "Manggilan" in Sabah and "Tulong" in Brunei. In Sarawak, it found in mixed dipterocarp and kerangas forest in areas above 610 meter. The timber is classified as softwood which belongs to a taxanomic group of gymnosperm and is light in weight (Ismail et al. 1999). This paper described the analysis of $A$. borneensis resin and bark oil constituents by using capillary gas chromatography-flame ionization detector (GC-FID) and gas chromatography-mass spectrometer (GC/MS).

\section{MATERIALS \& METHODS}

\section{Plant materials}

The resin and fresh bark samples of $A$. borneensis were collected from Bario Highland, Miri Division of Sarawak. The resin was ground into powder while the bark was milled into small meals.

\section{Oil isolation}

The bark and resin samples were subjected to water distillation using a Clavenger-type apparatus. Approximately $300 \mathrm{~g}$ of fresh bark meals and $30 \mathrm{~g}$ of ground resin were weighted, transferred to $2 \mathrm{~L}$ flat round bottom flask and mixed with $1.5 \mathrm{~L}$ of distilled water. The flask was assembled to the clavenger trap, connected to the condenser and heated. The hydrodistillation process was carried out for eight hours. After eight hours the oil trap in the clavenger was then cooled at room temperature. The oily layer obtained was separated and any trace water remained in the oil was adsorbed with anhydrous sodium sulfate. The percentage of the oil was calculated based on dried weight of the resin and bark samples.

\section{Gas chromatographic analysis of the essential oil}

GC analysis of the essential oil was performed on a Hewlett Packard gas chromatograph model HP-6890 equipped with flame ionization detector (FID) and an HP-5 fused capillary column $(5 \%$ phenylmethylpolysiloxane stationary phase) with film

*Corresponding author: zaini@frst.unimas.my 
thickness of $0.25 \mu \mathrm{m}, 30 \mathrm{~m}$ length and $0.25 \mathrm{~mm}$ internal diameter. The temperature for injector and detector were programmed at $260^{\circ} \mathrm{C}$ and $280^{\circ} \mathrm{C}$, respectively. The $\mathrm{GC}$ oven temperature was programmed from $50^{\circ} \mathrm{C}$ for five minutes, then increased at $3.5^{\circ} \mathrm{C} / \mathrm{min}$ to $280^{\circ} \mathrm{C}$ and hold at final temperature for five minutes. Prior to injection, 1.0 $\mu \mathrm{L}$ of essential oil was diluted with $199 \mu \mathrm{L}$ of dichloromethane. Exactly $1 \mu \mathrm{L}$ of diluted oil was then injected using a microsyringe to GC column in a splitless mode. Hydrogen was used as carrier gas with a flow rate of $1 \mathrm{~mL} / \mathrm{min}$. Diluted essential oil was also analyzed on a Shimadzu gas chromatography-mass spectrometer (GC-MS) model QP 2010 PLUS equipped with a quadrapole mass analyser. The GC column was BPX-5 (5\% phenyl polysilphenylene-siloxane) with film thickness of $0.25 \mu \mathrm{m}, 30 \mathrm{~m}$ length and $0.25 \mathrm{~mm}$ internal diameter. The injection mode and temperature program used were similar to GC-FID analysis. Helium was used as carrier gas with a flow rate of $1 \mathrm{~mL} / \mathrm{min}$. Identification of oil components was achieved based on their Kovat's indices (KI) by using authentic n-alkanes standard $\left(\mathrm{C}_{9}\right.$ to $\left.\mathrm{C}_{32}\right)$ as references and further confirmed by library search against the mass spectral library in NIST08 database incorporated with GC-MS data system.

\section{RESULTS \& DISCUSSION}

Hydrodistillation of $A$. borneensis resin obtained yellow oil with $7.3 \%$ yield (based on dry weight). Gas chromatographic analysis of the resin oil identified 51 compounds as constituents of the oil. The gas chromatograms obtained from GC-FID and GC-MS analyses of the resin oil are shown in Figures 1 and 2, respectively. The chemical constituents identified in the resin oil are listed in Table 1. Approximately $3.02 \%$ of the chemical constituents of resin oil was not identified due to poor similarity index of these components during the library search with NIST mass spectral library of GC-MS. The chromatographic analysis showed that the major constituents in the resin essential oil were $\alpha$-pinene, $\delta$-limonene, $\beta$-pinene and terpinen-4-ol. $\alpha$-pinene showed the highest percentage which is $30.93 \%$, followed by d-limonene $(17.79 \%)$, $\beta$ pinene $(11.28 \%)$ and terpinen-4-ol $(8.35 \%)$.
Hydrodistillation of fresh $A$. borneensis bark sample yielded $0.49 \%$ yellow oil. Bark essential oil consists of 60 compounds as confirmed by GC-FID and GCMS analytical data. The analysis showed that the major components identified in the bark essential oil were $\beta$-pinene $(8.68 \%)$, terpinen-4-ol $(8.54 \%), \alpha$ pinene $(8.50 \%)$ and $\alpha$-terpineol $(8.48 \%)$. The gas chromatograms obtained from GC-FID and GC-MS analyses of the bark essential oil are shown in Figures 3 and 4, respectively. The compounds identified in the bark essential oil are presented in Table 2. Approximately $14.39 \%$ of chemical constituents in A. borneensis bark oil remained unidentified by both GC-FID and GC-MS.

The essential oils of resin and bark samples contained several similar major components such as $\alpha$-pinene, $\beta$-pinene and terpinen-4-ol. However, the percentage of $\alpha$-pinene in the resin oil was higher compared to the bark oil with $30.93 \%$ and $8.50 \%$, respectively. The amount of $\beta$-pinene was also higher in the resin oil compare to the bark oil with $11.28 \%$ and $8.68 \%$, respectively. Interestingly, the resin and bark oils consists of almost similar quantity of terpinen-4-ol with $8.35 \%$ and $8.54 \%$, respectively.

Data on chemical composition of essential oils from genus of Agathis is limited. Brophy et al. (2000) reported the major compounds detected in the essential oil from four species of Agathis such as A. microstachya, A. robusta, $A$. australis and $A$. atropurpurea. The major compound identified in the essential oil from A. microstachya was the monoterpene $\alpha$-pinene $(17.9 \%)$. The main components in the essential oil of $A$. robusta were $\alpha$ pinene, $\beta$-pinene, $\beta$-caryophyllene, $\delta$-germacrene, $\delta$-cadinene, caryophyllene oxide and spathulenol. The chemical components identified in the essential oil of $A$. australis were $\delta$ - $\alpha$-pinene, $\delta$-camphene, $\delta$ limonene, dipentene, 1,8-cineole, $\delta$-borneol, 1cadinene, kaurene, tricyclene, car-3-ene, p-cymene, terpinolene, $\alpha$-copaene, aromadendrene, $\quad \gamma$ muurolene, isophyllocladene, isoatisirene, isopimara-8,15-diene, dehydroabietane, $\delta$ germacrene, bicyclogermacrene, 16-kaurene, sclarene and 8- $\beta$-hydroxysandarocopimar-15-ene. While, the essential oils from A. atropurpurea contains $\alpha$-pinene, $\alpha$-copaene, bicyclogermacrene, $\delta$-cadinene, phyllocladene and 16-kaurene as it major components. 


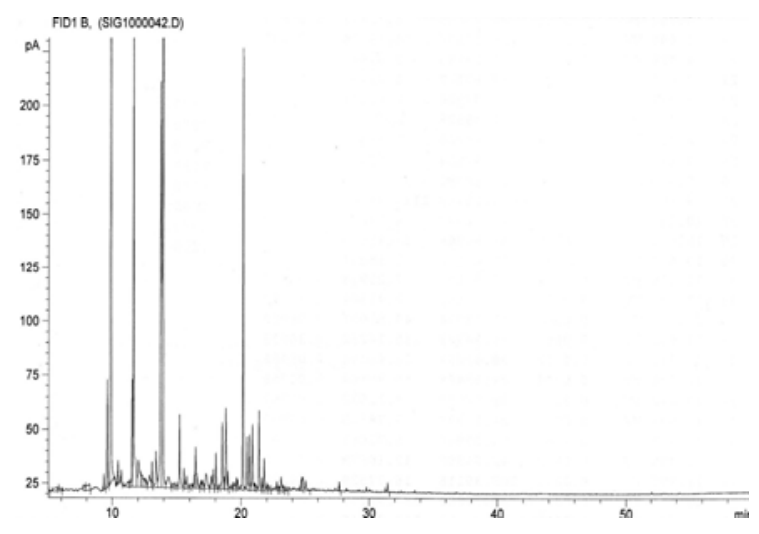

Figure 1. Gas chromatogram traced by GC-FID of $A$. borneensis resin oil.

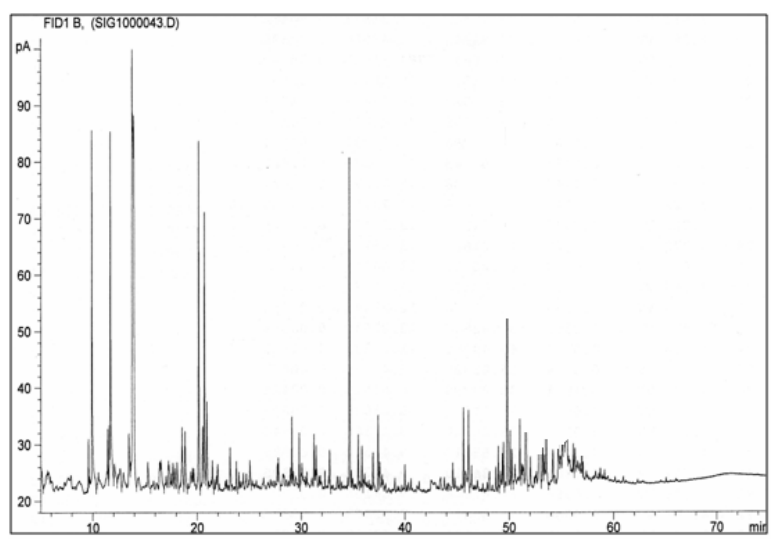

Figure 3. Gas chromatogram traced by GC-FID of $A$. borneensis bark oil.

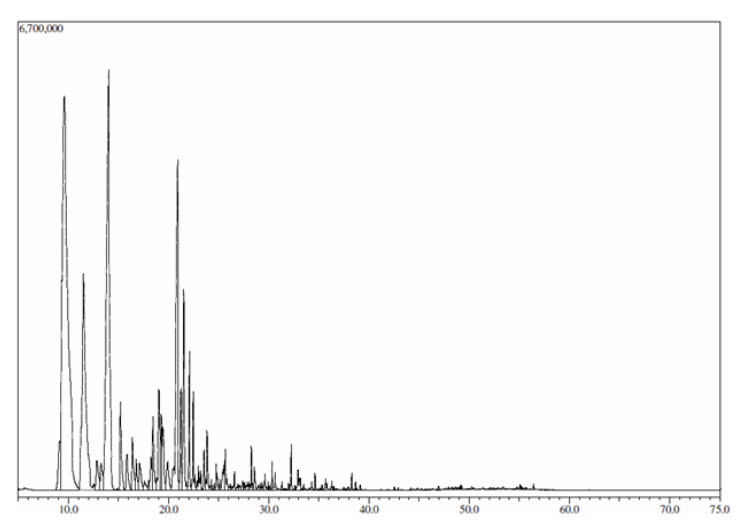

Figure 2. Gas chromatogram traced by GC-MS of $A$. borneensis resin oil

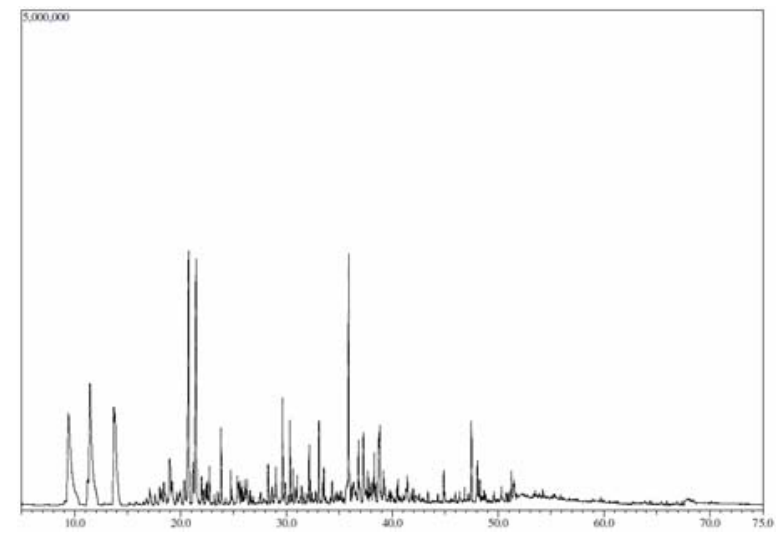

Figure 4. Gas chromatogram traced by GC-MS of $A$. borneensis bark oil

Table 1. Chemical constituents of the essential oil from resin of $A$. borneensis

\begin{tabular}{|c|c|c|c|}
\hline Compound name & Kovat's Index & $\%$ area & Identification \\
\hline$\alpha$-pinene & 940 & 30.93 & $a, b$ \\
\hline$\beta$-pinene & 983 & 11.28 & $a, b$ \\
\hline 3-carene & 1013 & 0.96 & $a, b$ \\
\hline$\alpha$-terpinene & 1023 & 0.80 & $a, b$ \\
\hline D-limonene & 1039 & 17.79 & $a, b$ \\
\hline$\gamma$-terpinene & 1065 & 1.80 & $a, b$ \\
\hline Sabinene hydrate & 1079 & 1.01 & $a, b$ \\
\hline Terpinolene & 1091 & 1.15 & $a, b$ \\
\hline$\alpha, p$-dimethylstyrene & 1100 & 0.62 & $a, b$ \\
\hline Linalool & 1108 & 0.80 & $a, b$ \\
\hline Limonene oxide & 1119 & 0.27 & $a, b$ \\
\hline Trans-dihydrocarvone & 1129 & 0.16 & $a, b$ \\
\hline Cis- $\beta$-terpineol & 1134 & 0.72 & $\mathrm{a}, \mathrm{b}$ \\
\hline$\alpha$-campholenic aldehyde & 1139 & 1.36 & $a, b$ \\
\hline 2(10)-pinen-3-ol & 1152 & 2.34 & $a, b$ \\
\hline 2-pinen-4-ol & 1157 & 1.22 & $a, b$ \\
\hline Dihydro- $\alpha$-terpineol & 1161 & 1.61 & $a, b$ \\
\hline 2-(4-methylcyclohexyl)-1-propanol & 1173 & 0.88 & $a, b$ \\
\hline
\end{tabular}




\begin{tabular}{lccc} 
Terpinen-4-ol & 1195 & 8.35 & $\mathrm{a}, \mathrm{b}$ \\
p-cymen-8-ol & 1203 & 1.60 & $\mathrm{a}, \mathrm{b}$ \\
$\alpha$-terpineol & 1210 & 3.18 & $\mathrm{a}, \mathrm{b}$ \\
2-pinen-4-one & 1224 & 1.86 & $\mathrm{a}, \mathrm{b}$ \\
Cis-carveol & 1234 & 1.21 & $\mathrm{a}, \mathrm{b}$ \\
Carveol & 1246 & 0.60 & $\mathrm{a}, \mathrm{b}$ \\
Epoxy linalooloxide & 1268 & 0.89 & $\mathrm{a}, \mathrm{b}$ \\
Linalool formate & 1278 & 0.10 & $\mathrm{a}, \mathrm{b}$ \\
3,3,5-trimethylcyclohexyl acetate & 1290 & 0.42 & $\mathrm{a}, \mathrm{b}$ \\
p-cymene-7-ol & 1308 & 0.62 & $\mathrm{a}, \mathrm{b}$ \\
6-methylspiro[4.5]decan-6-ol & 1314 & 0.72 & $\mathrm{a}, \mathrm{b}$ \\
Carvone hydrate & 1359 & 0.17 & $\mathrm{a}, \mathrm{b}$ \\
$\alpha$-cubebene & 1382 & 0.44 & $\mathrm{a}, \mathrm{b}$ \\
$\alpha$-bergamotene & 1438 & 0.24 & $\mathrm{a}, \mathrm{b}$ \\
$\beta$-sesquiphellandrene & 1446 & 0.22 & $\mathrm{a}, \mathrm{b}$ \\
$\alpha$-santalol & 1465 & 0.10 & $\mathrm{a}, \mathrm{b}$ \\
$\beta$-farnesene & 1491 & 0.39 & $\mathrm{a}, \mathrm{b}$ \\
o-menth-8-ene-4-methanol & 1560 & 0.17 & $\mathrm{a}, \mathrm{b}$ \\
Unidentified components & - & 3.02 & \\
\hline
\end{tabular}

Notes: a - Kovat's Index ; b - GC-MS library.

Table 2. Chemical constituents of the essential oil from bark of $A$. borneensis

\begin{tabular}{|c|c|c|c|}
\hline Compound name & Kovat's Index & $\%$ area & Identification \\
\hline$\alpha$-pinene & 935 & 8.50 & $a, b$ \\
\hline$\beta$-terpinene & 976 & 0.72 & $a, b$ \\
\hline$\beta$-pinene & 981 & 8.68 & $a, b$ \\
\hline o-cymene & 1032 & 3.51 & $a, b$ \\
\hline$\alpha$-limonene & 1034 & 5.73 & $a, b$ \\
\hline Fenchol & 1129 & 0.59 & $a, b$ \\
\hline$\alpha$-campholenic aldehyde & 1138 & 0.44 & $a, b$ \\
\hline 2(10)-pinen-3-ol & 1151 & 2.03 & $a, b$ \\
\hline Verbenol & 1156 & 0.49 & $a, b$ \\
\hline Borneol & 1183 & 0.67 & $a, b$ \\
\hline Terpinen-4-ol & 1192 & 8.54 & $a, b$ \\
\hline$\rho$-cymen-8-ol & 1202 & 1.84 & $a, b$ \\
\hline$\alpha$-terpineol & 1209 & 8.48 & $a, b$ \\
\hline 2-pinen-4-one & 1222 & 0.84 & $a, b$ \\
\hline Cis-carveol & 1232 & 0.47 & $a, b$ \\
\hline 2-hydroxycineole & 1240 & 0.92 & $a, b$ \\
\hline Carvone & 1259 & 0.47 & $a, b$ \\
\hline Epoxy linalooloxide & 167 & 2.15 & $\mathrm{a}, \mathrm{b}$ \\
\hline 2,3-pinenediol & 1324 & 0.51 & $a, b$ \\
\hline$\alpha$-cubebene & 1381 & 1.08 & $a, b$ \\
\hline Cedr-8-ene & 1391 & 0.68 & $a, b$ \\
\hline$\alpha$-longipinene & 1418 & 1.96 & $a, b$ \\
\hline$\alpha$-bergamotene & 1438 & 1.56 & $a, b$ \\
\hline$\beta$-sesquiphellandrene & 1446 & 0.69 & $a, b$ \\
\hline
\end{tabular}




\begin{tabular}{|c|c|c|c|}
\hline$\beta$-farnesene & 1457 & 0.68 & $\mathrm{a}, \mathrm{b}$ \\
\hline Curcumene & 1488 & 1.09 & $a, b$ \\
\hline Farnesene epoxide & 1552 & 0.80 & $a, b$ \\
\hline Spathulenol & 1593 & 0.49 & $a, b$ \\
\hline (-)-isolongifolol & 1598 & 6.86 & $a, b$ \\
\hline (-)-globulol & 1600 & 0.68 & $a, b$ \\
\hline Guaiol & 1610 & 1.19 & $a, b$ \\
\hline Unidentified & 1620 & 0.51 & - \\
\hline 1,2-epoxide-humulene & 1626 & 1.46 & $a, b$ \\
\hline Cubenol & 1629 & 0.72 & $a, b$ \\
\hline $\begin{array}{l}3,5,6,7,8,8 \alpha \text {-hexahydro- } 4,8 \alpha- \\
\text { dimethyl-6-(1-methylethenyl)- } \\
\text { 2(1H)naphthalenone }\end{array}$ & 1640 & 2.48 & $\mathrm{a}, \mathrm{b}$ \\
\hline Guai-1(10)-en-11-ol & 1654 & 0.64 & $a, b$ \\
\hline$\gamma$-muurolene & 1662 & 0.48 & $\mathrm{a}, \mathrm{b}$ \\
\hline$\alpha$-bisabolol oxide & 1668 & 0.53 & $a, b$ \\
\hline 1-tetradecanol & 1686 & 2.59 & $a, b$ \\
\hline$\alpha$-bisabolol & 1699 & 0.64 & $a, b$ \\
\hline Unidentified & 1744 & 0.45 & - \\
\hline $\begin{array}{l}\text { 1,5,5,8-tetramethyl-3,7- } \\
\text { cycloundecadien-1-ol }\end{array}$ & 1769 & 0.59 & $\mathrm{a}, \mathrm{b}$ \\
\hline 1-nonadecene & 1890 & 0.67 & $a, b$ \\
\hline 8-epimanoyl oxide & 2011 & 0.51 & $\mathrm{a}, \mathrm{b}$ \\
\hline Unidentified Components & - & 14.39 & - \\
\hline
\end{tabular}

Notes: a - Kovat's Index ; b - GC-MS library.

\section{CONCLUSION}

The chemical constituents in the resin and bark oil of A. borneensis have been determined. The major components identified in the resin essential oil were $\alpha$-pinene, $\delta$-limonene, $\beta$-pinene and terpinen-4-ol. On the other hand, $\beta$-pinene, terpinen-4-ol , $\alpha$-pinene and $\alpha$-terpineol were detected as major components in the bark essential oil.

\section{ACKNOWLEDGEMENT}

Authors would like to thank the Universiti Malaysia Sarawak for financial support through Postgraduate Fellowship Scheme to Fouziah Binti Alet.

\section{REFERENCES}

Appanah, S. \& Weinland, G. (1993). Planting Quality Timber Trees in Peninsular Malaysia: A Review. Kuala Lumpur : Forest Research Institute Malaysia , pp 121-180.Brophy, J. J., Goldsack, R. J., Wu, M. Z., Fookes, C. J. R. and Forster, P. I. 2000. The Steam Volatile Oil of Wollemia nobilis and Its Comparison with Other Members of the Araucariaceae (Agathis and Araucaria). Biochemical Systematic and Ecology, 28: 563578.

Ismail, J., Ipor, I. B. \& Tawan, C.S. (1999). Specific gravity of Agathis borneensis Warb. of Kelabit Highlands. ASEAN Review of Biodiversity and Environmental Conservation (ARBEC), pp 1-7.

Savluchinske-Feio, S., Curto, M. J. M., Gigante, B. \& Roseiro, J. C. (2006). Antimicrobial activity of resin acid derivatives. Applied Microbiology and Biotechnology, 72: 430-436. 